\title{
MicroRNA-372 inhibits endometrial carcinoma development by targeting the expression of the Ras homolog gene family member C (RhoC)
}

\author{
Bo-Liang Liu' ${ }^{1}$, Kai-Xuan Sun ${ }^{1}$, Zhi-Hong Zong ${ }^{2}$, Shuo Chen ${ }^{1}$, Yang Zhao ${ }^{1}$ \\ ${ }^{1}$ Department of Gynecology, The First Affiliated Hospital of China Medical University, Shenyang 110001, China \\ ${ }^{2}$ Department of Biochemistry and Molecular Biology, College of Basic Medicine, China Medical University, Shenyang 100013, China \\ Correspondence to: Yang Zhao, e-mail: yida.zhaoyang@163.com \\ Keywords: endometrial carcinoma, microRNA-372, RhoC, tumorigenesis, progression \\ Received: July 23, $2015 \quad$ Accepted: November 16, $2015 \quad$ Published: December 09, 2015
}

\section{ABSTRACT}

Here we explore the role of microRNA-372 (miR-372) in tumorigenesis and development of endometrial adenocarcinoma (EC) and analyze the underlying mechanism. We found that miR-372 expression is much lower in EC than normal endometrial specimens. Cell function experiments demonstrated that miR-372 overexpression suppressed cell proliferation, migration, and invasion, and led to a G1 phase arrest and promoted the apoptosis of endometrial carcinoma cells in vitro. The nude mouse xenograft assay demonstrated that miR-372 overexpression suppressed tumor growth. RT-PCR and Western blot assays detected the expression of known targets of miR-372 in other malignant tumors and found Cyclin A1 and Cyclin-dependent Kinase 2 (CDK2) was downregulated by miR-372. Bioinformatic predictions and dualluciferase reporter assays found that RhoC was a possible target of miR-372. RTPCR and Western blot assays demonstrated that miR-372 transfection reduced the expression of RhoC, matrix metalloproteinase 2 (MMP2) and MMP9, while it increased the expression of cleaved poly (ADP ribose) polymerase (PARP) and bcl-2-associated $X$ protein (Bax). The cell function experiments that transfected siRNA with RhoC showed the same trend as those which were transfected with miR-372. Taken together, our results demonstrated for the first time that miR-372 suppresses tumorigenesis and the development of EC; RhoC is a new and potentially important therapeutic target.

\section{INTRODUCTION}

Endometrial cancers are one of the most common gynecological cancers in many developed countries [1]. In 2015, the American Cancer Society (ACS) estimates that 54,870 women will be diagnosed with endometrial cancer and 10,170 women will die from this disease [2]. Therefore, it is essential to dissect the underlying molecular mechanisms of tumorigenesis and development of EC for better diagnosis and treatment.

MicroRNAs (miRNAs), a class of small non-coding RNAs (21-23 nt in length), repress the expression of target genes at the post-transcriptional level by binding to the 3'UTR of their target mRNAs to induce degradation or restrain translation [3-4]. MiRNAs have important functions in the development of cell differentiation and the regulation of the cell cycle and apoptosis [5-9]. In the present study, we focus on miR-372, which has been demonstrated to act as an anti-oncogenic miRNA in both cervical carcinoma and hepatocellular carcinoma, and to act as an oncogenic miRNA in testicular germ cell tumors, human embryonic stem cells (hESCs), head and neck squamous cell carcinoma (HNSCC), and colorectal cancer. However, the role of miR-372 in endometrial cancer remains unclear. Our results show that miR-372 suppresses the tumorigenesis and development of EC.

\section{RESULTS}

Correlation of miR-372 expression with the pathogenesis and aggressiveness of endometrial carcinoma

The expression levels of miR-372 were analyzed in endometrial carcinoma samples and normal samples by qRT-PCR. As shown in Figure 1A, miR-372 expression 
levels were lower in EC tissues than those in normal samples $(P<0.05$, Figure 1B), and in lymph nodes metastasis $(+)$ than those in lymph nodes metastasis $(-)$ $(P<0.05$, Figure 1C). Besides, miR-372 expression was lower in estrogen receptor (ER) and progesterone receptor (PR) negative tissues than in ER and PR positive tissues $(P<0.05$, Figure 1D \& 1E).

\section{MiR-372 overexpression suppresses endometrial carcinoma cell proliferation}

The miR-372 mimics were transfected into cells to upregulate miR-372 expression. We analyzed miR-372 levels after transfection by qRT-PCR and found that miR-372 levels were significantly increased $(P<0.05$; Figure $2 \mathrm{~A})$.

A

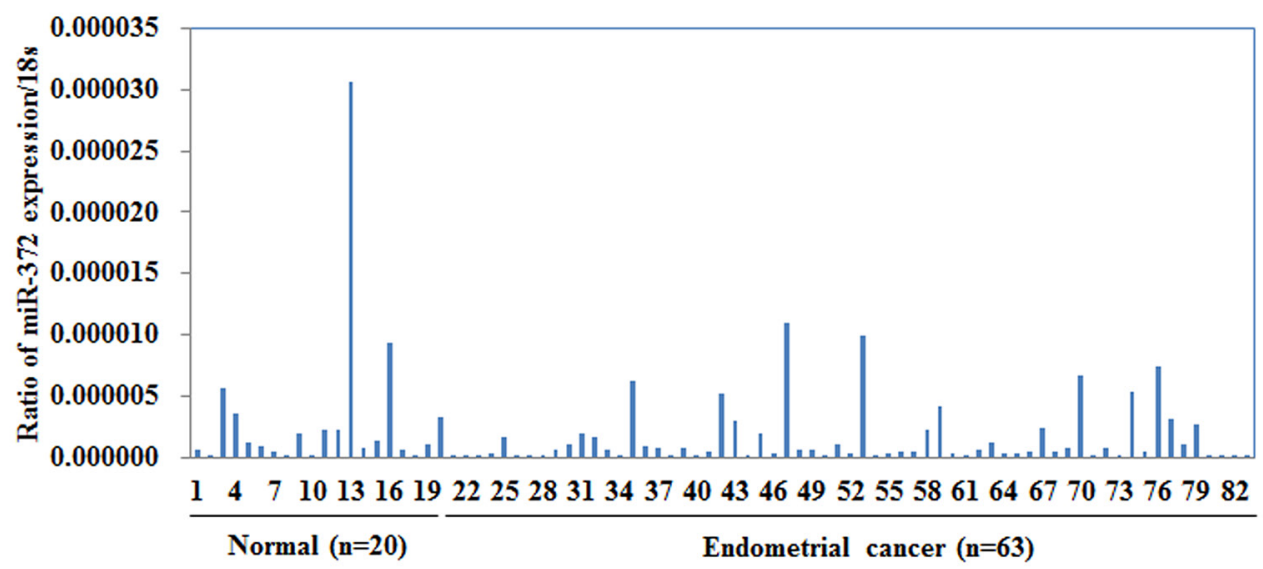

B

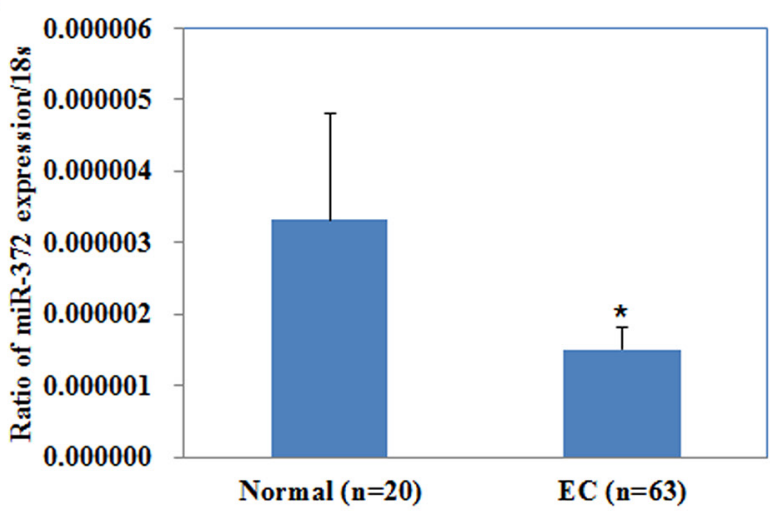

D

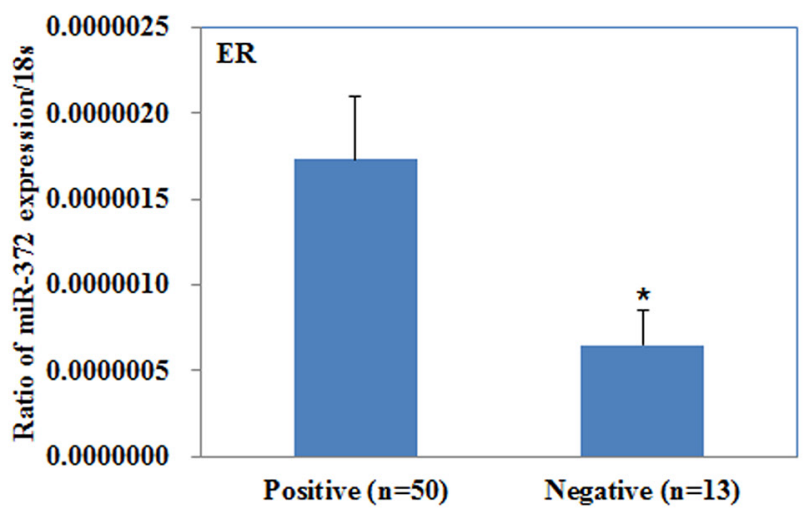

C

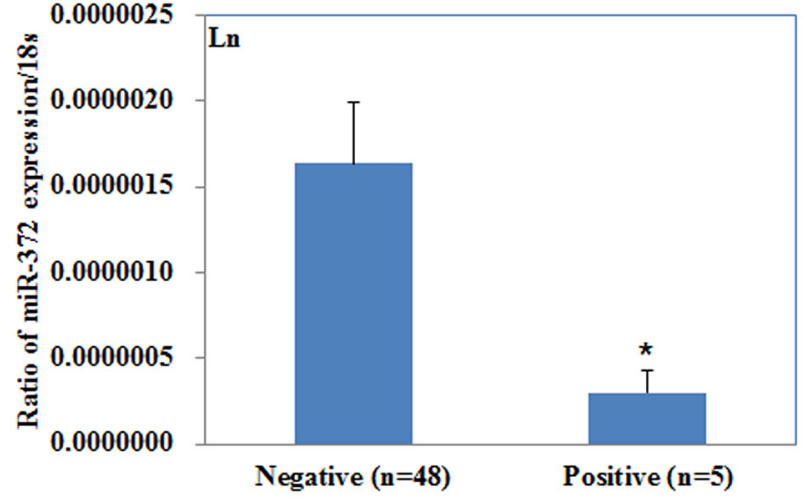

E

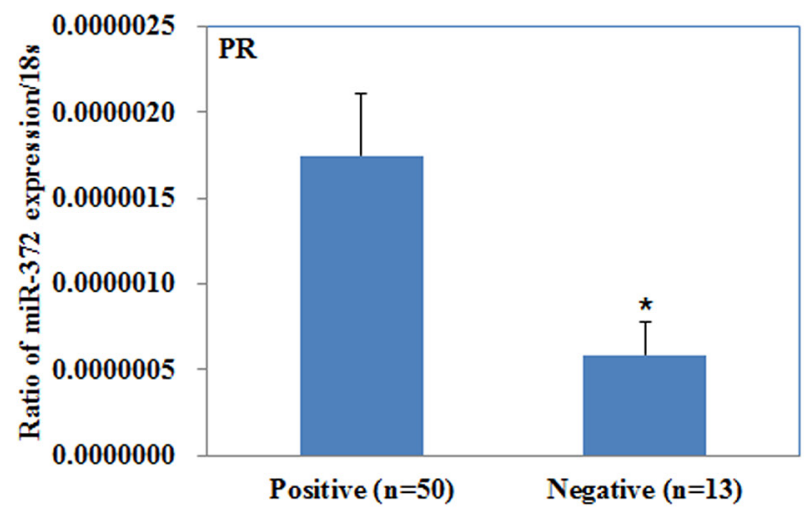

Figure 1: Correlation of miR-372 expression with pathogenesis and aggressiveness of endometrial carcinoma. MiR-372 mRNA expression was significantly lower in endometrial adenocarcinoma than in normal endometrial tissues $\mathbf{A} / \mathbf{B}$. and was negatively associated with Lymph node metastasis C. positively associated with ER D. and PR expression E. EC = endometrial adenocarcinoma, ER = estrogen receptor, $\mathrm{PR}=$ progesterone receptor. 
We performed a MTT proliferation assay after miR372 transfection. A significant reduction of cell viability was observed 48, and 72 hours after transfection with the miR-372 mimics compared with control and mocktransfected cells $(P<0.05$; Figure $2 \mathrm{~B})$.

\section{MiR-372 overexpression induces G1 phase arrest and promotes apoptosis of endometrial carcinoma cells}

Cell cycle analysis demonstrated that miR372 transfection increased the percentage of cells in G1 phase versus control and mock-transfected cells $(P<0.05$; Figure 3A). Apoptosis assays demonstrated that cell apoptosis rates were elevated 48 hours after transfection with the miR-372 mimics compared with control and mock-transfected cells $(P<0.05$; Figure $3 \mathrm{~B})$.

\section{MiR-372 overexpression suppresses endometrial carcinoma cell migration and invasion}

Our wound-healing assay showed that cells overexpressing miR-372 presented a slower closing of the scratch wound compared with the control and mock-transfected cells $(P<0.05$; Figure 4A). Transwell assays showed that the cells transfected with miR-372 significantly reduced the ability to invade compared with control and mock-transfected cells $(P<0.05$; Figure 4B).

\section{MiR-372 overexpression suppresses the tumori- genicity of endometrial carcinoma cells in vivo}

We performed nude mice xenograft assays and demonstrated that, compared with the control group, in mice injected with the HSA-372 transfection cells tumorigenicity was slower (Figure 5A \& 5B) and, given the same duration of observation, the volume of tumors was smaller $(P<0.05$; Figure 5C).

\section{Cyclin A1 and CDK2 were downregulated} in endometrial carcinoma cells transfected with miR-372, and in the tumor tissues of the HSA-372 group of nude mice, while ATAD2, Lats2, P21, P62, and DKK1 demonstrated no significant differences in expression

We performed Western blot and RT-PCR analysis to detect the expression of Cyclin A1, CDK2, ATAD2, Lats2, P21, P62, and DKK1 in EC cells transfected with
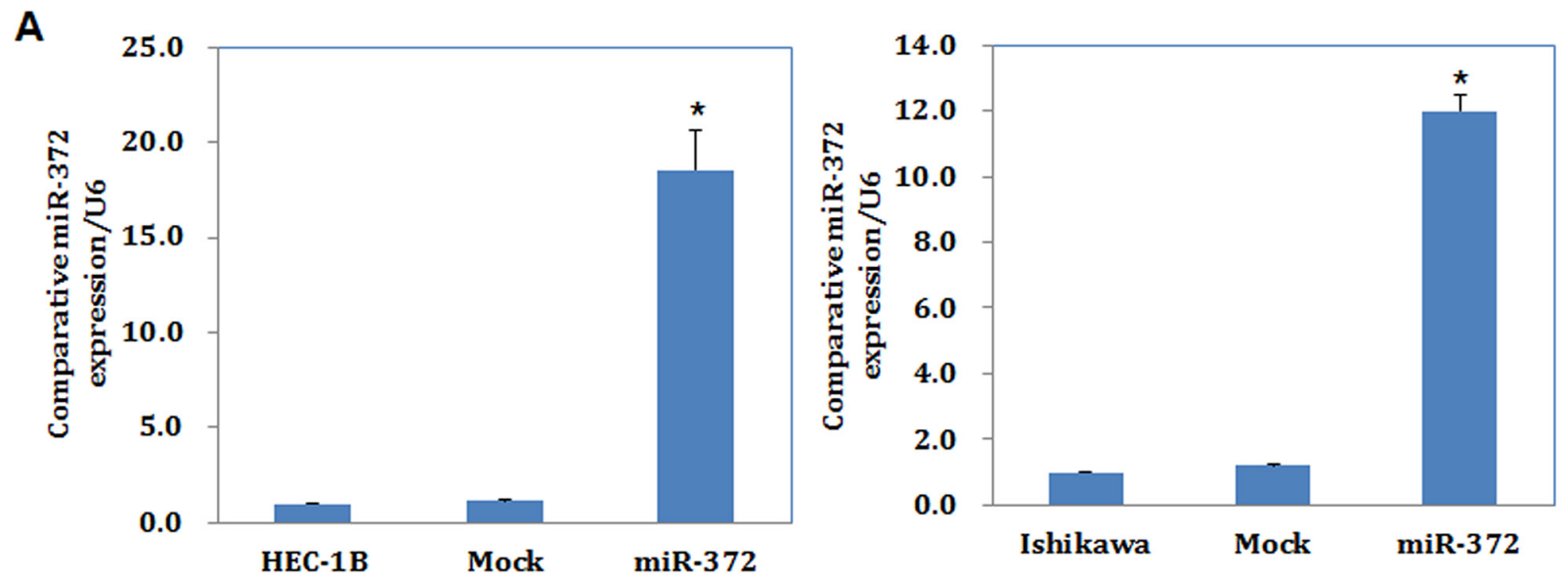

B

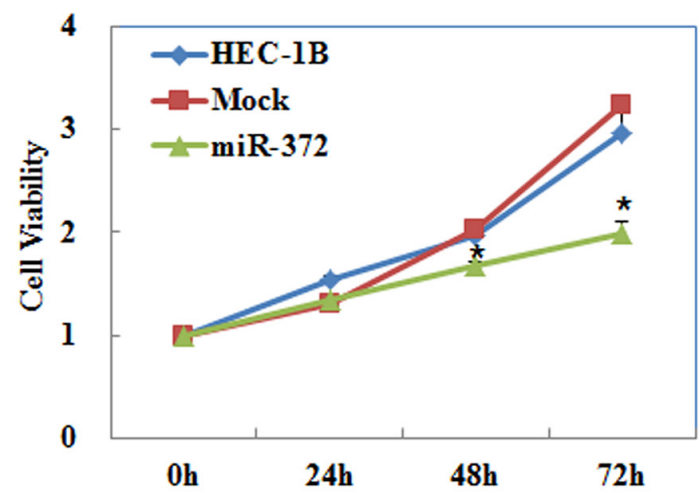

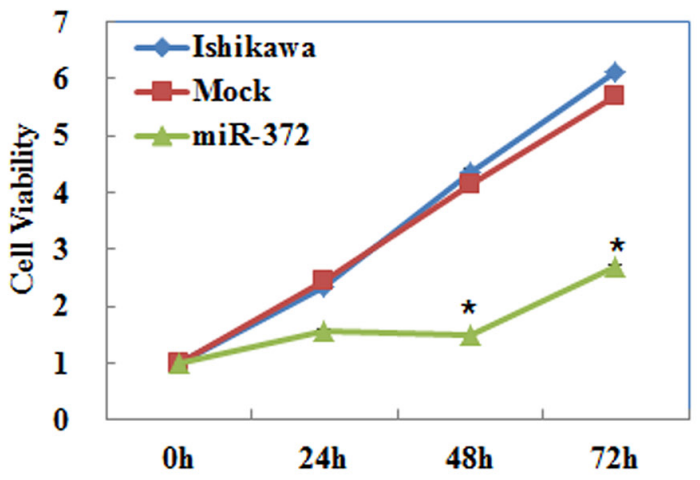

Figure 2: MiR-372 overexpression suppresses endometrial carcinoma cell proliferation in vitro. Following miR-372 transfection, endometrial adenocarcinoma cell lines exhibited significantly higher miR-372 expression A. and slower growth B. compared with the control and mock cells. Results are representative of three separate experiments; data are expressed as the mean \pm standard deviation, $* P<0.05$. 
miR-372. We showed that Cyclin A1 and CDK2 were downregulated at the protein and mRNA level compared with the negative control. However, ATAD2, Lats2, P21, P62, and DKK1 showed no significant differences in expression level $(P<0.05$; Figure 6A \& 6B). Western blot analysis also demonstrated the same trend, with the expression of Cyclin A1 and CDK2 being downregulated in the tumor tissues of the HSA-372 group of nude mice. Other genes showed no significant differences $(P<0.05$; Figure 6C).

\section{RhoC is a target of miR-372}

According to a prediction website (http://microRNA. org), we found that the complementary sequence of miR-372 was found in the 3'UTR of RhoC $(P<0.05$; Figure 7A). We performed luciferase reporter assays with the wild-type or mutant 3'UTR of RhoC. Our results demonstrate that miR372 significantly decreased the relative luciferase activity of the wild-type RhoC 3'UTR compared with the mutant RhoC 3'UTR, indicating that miR-372 may directly bind to
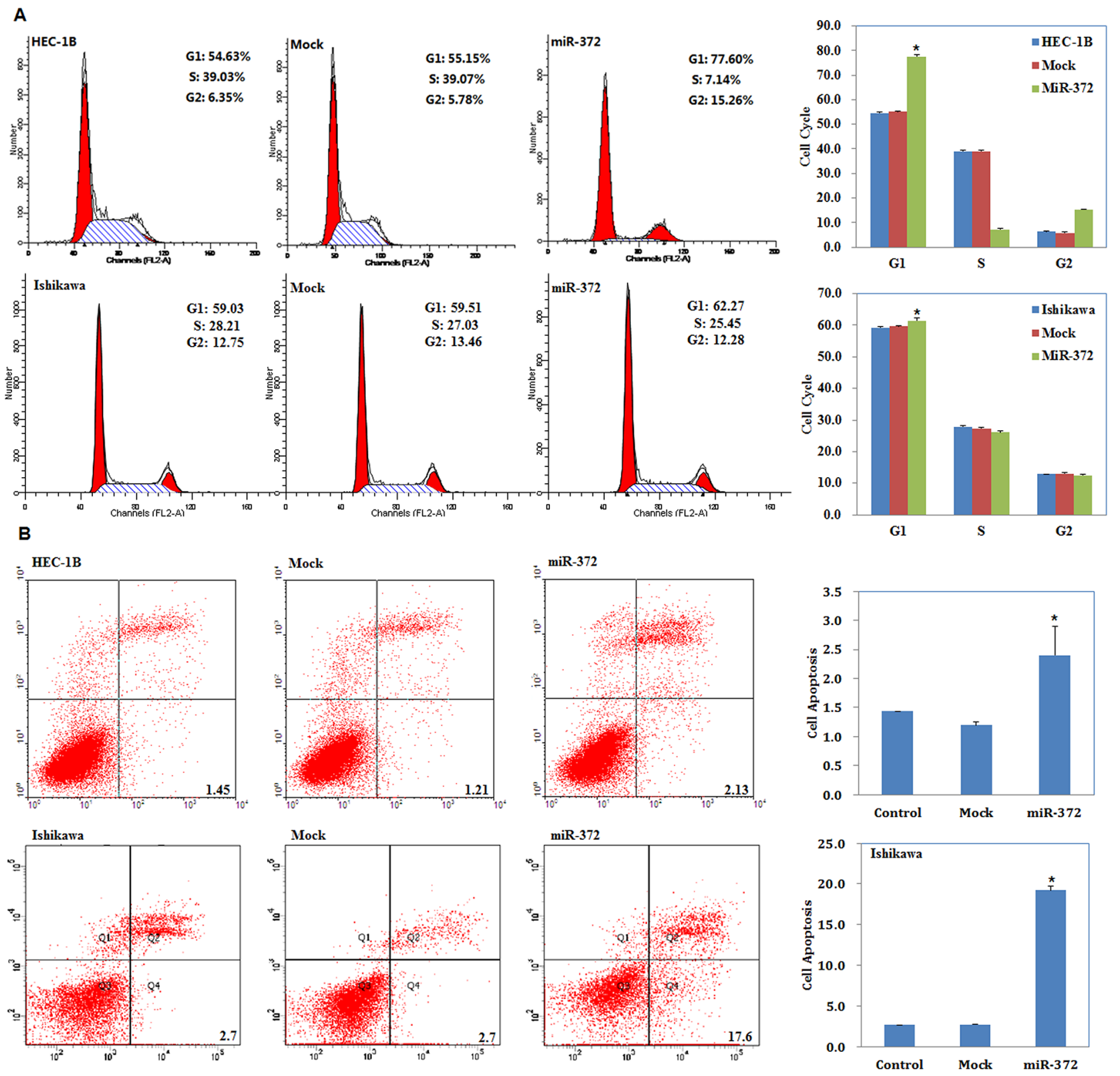

Figure 3: MiR-372 overexpression induces G1 phase arrest and promotes apoptosis of endometrial carcinoma cells. Following miR-372 transfection, endometrial adenocarcinoma cell lines exhibited significantly induced G1 arrest A. and elevated apoptosis B. compared with the control and mock cells. Results are representative of three separate experiments; data are expressed as the mean \pm standard deviation, ${ }^{*} P<0.05$. 
the 3'UTR of RhoC $(P<0.05$; Figure 7B). QRT-PCR and Western blot analysis showed that the miR-372 transfection reduced the expression of $\mathrm{RhoC}$ at both $\mathrm{mRNA}$ and protein levels $(P<0.05$; Figure $7 \mathrm{C})$. Immunohistochemical analysis and Western blot demonstrated a significant reduction of RhoC expression in the HSA-372 group compared with the control group in nude mice tumor tissues $(P<0.05$; Figure $8 \mathrm{~A} \& 8 \mathrm{~B})$. Taken together, these results suggest that RhoC is a direct target of miR-372.

\section{siRhoC transfection suppresses endometrial carcinoma cell proliferation}

siRhoC was transfected into cells to reduce RhoC expression. We performed a MTT proliferation assay after cells were transfected with siRhoC. A significant reduction of cell viability was observed 48 , and 72 hours after transfection with siRhoC compared with control and mock-transfected cells $(P<0.05$; Figure 9A).

A

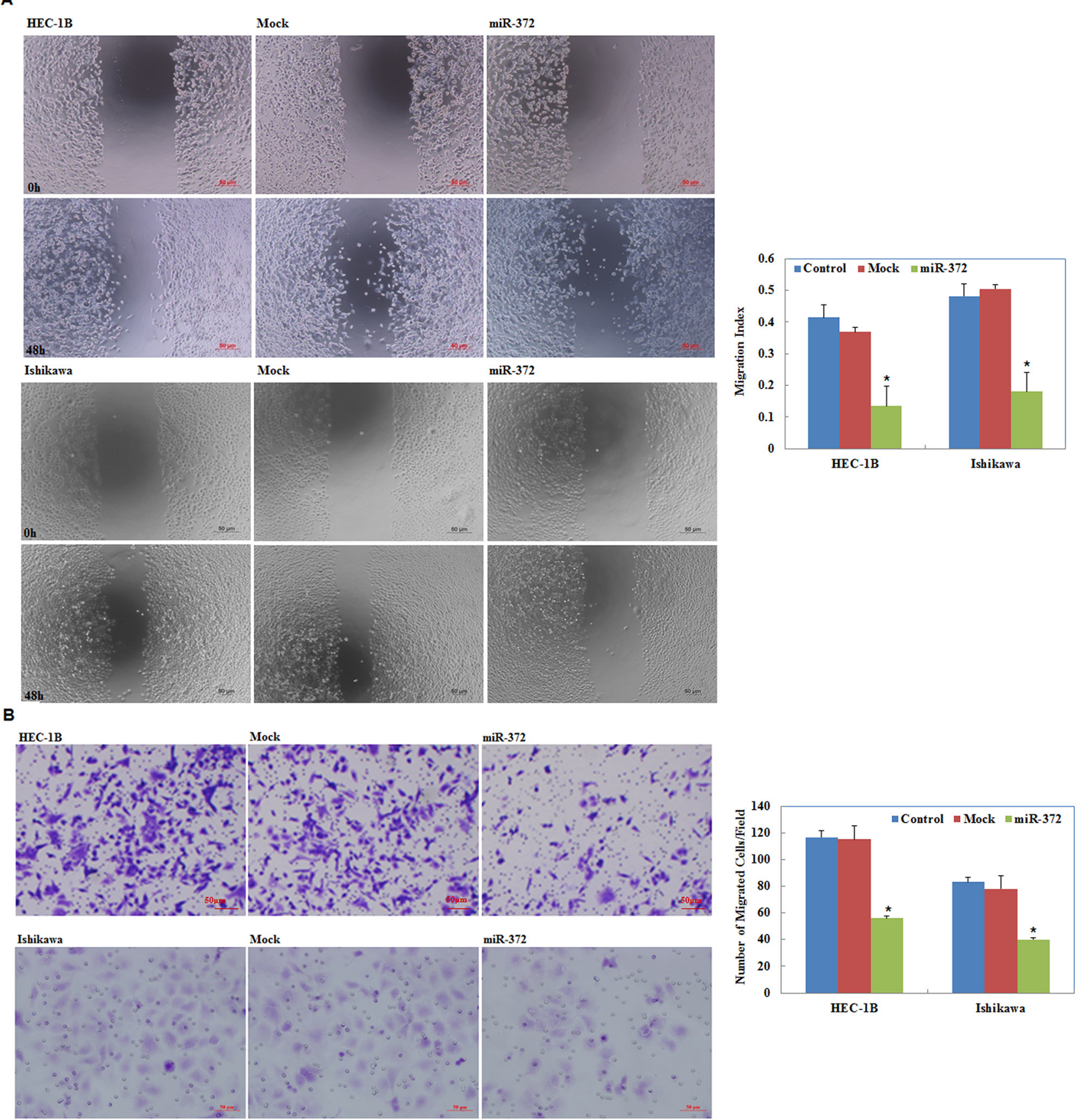

Figure 4: Effects of miR-372 transfection on invasive and metastatic ability of endometrial adenocarcinoma cell lines in vitro. Following miR-372 transfection, endometrial adenocarcinoma cell lines exhibited lower migration in wound healing assays A. and slower invasion in Transwell assays B. compared with the control and mock cells. Results are representative of three separate experiments; data are expressed as the mean \pm standard deviation, ${ }^{*} P<0.05$. 
A

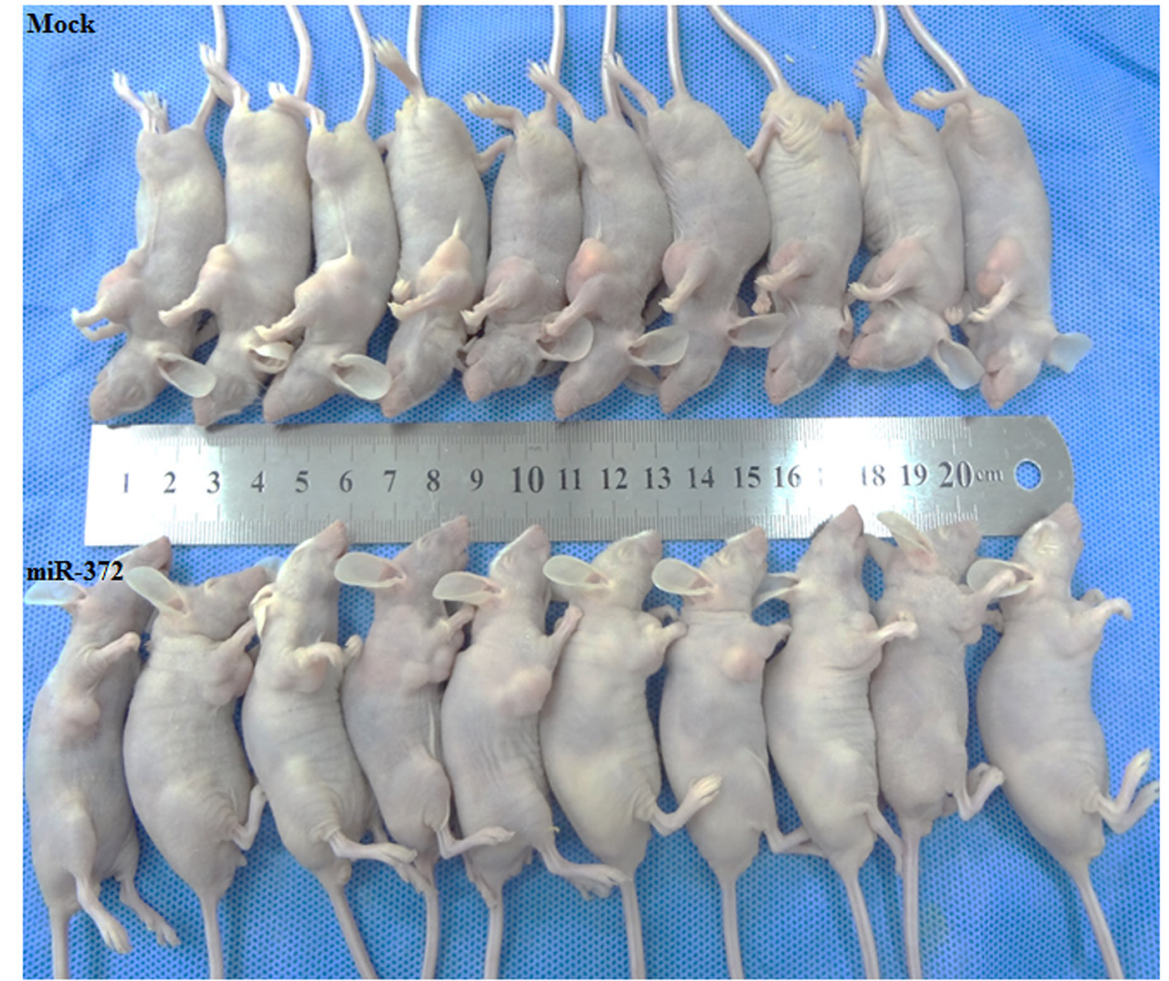

B

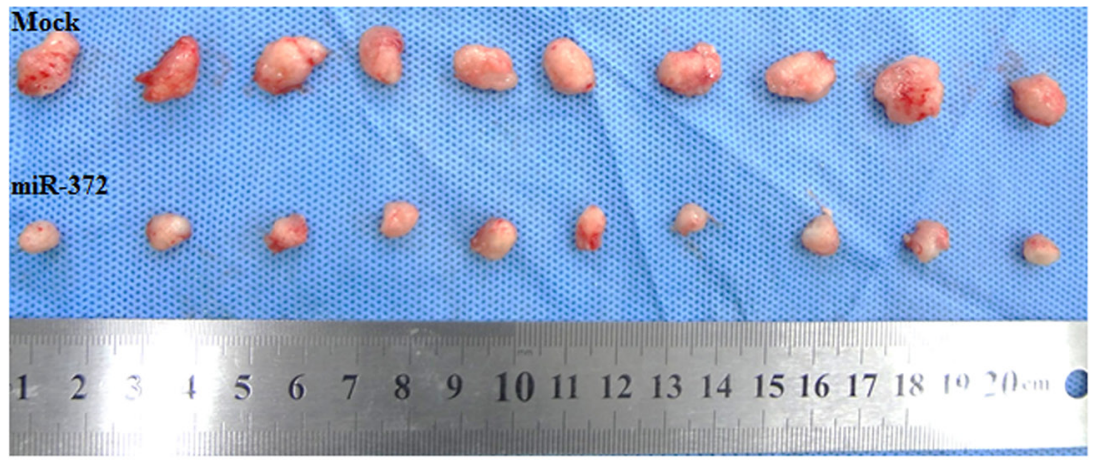

C

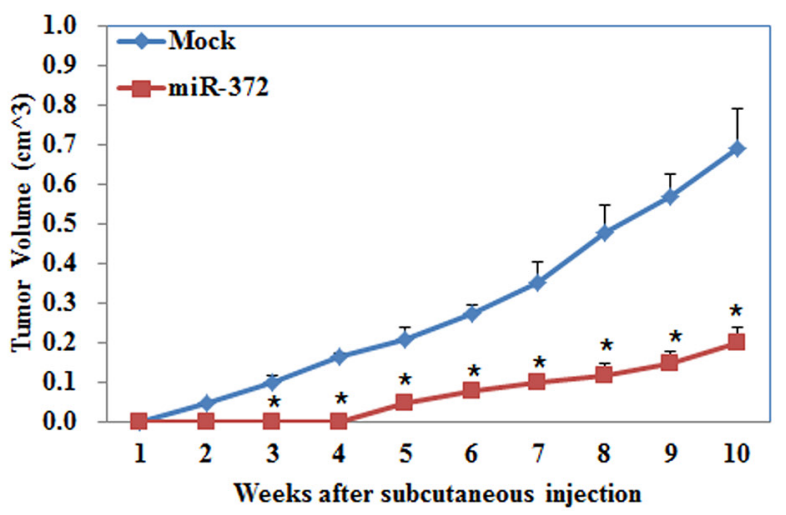

Figure 5: MiR-372 inhibited tumor growth in vivo. Tumor xenograft volume in nude mice treated with miR-372 was smaller than that in mock nude mice A \& B. Tumor xenograft growth in miR-372-treated nude mice was slower than that in the control group $\mathbf{C}$. $* P<$ 0.05 . 


\section{siRhoC induces G1 phase arrest and promotes apoptosis of endometrial carcinoma cells}

Cell cycle analysis demonstrated that after transfection with siRhoC the percentage of cells in G1 phase increased when compared with control and mocktransfected cells $(P<0.05$; Figure 9B).

Apoptosis assays demonstrated that apoptosis rates were elevated 48 hours after transfection with siRhoC compared with control and mock-transfected cells $(P<$ 0.05; Figure 9C).

\section{siRhoC suppresses endometrial carcinoma cell migration and invasion}

Our wound-healing assay showed that cells transfected with siRhoC had slower closing of scratch wounds compared with the control and mock-transfected cells $(P<0.05$; Figure 10A). Transwell assays showed that the cells transfected with siRhoC had significantly reduced ability to invade compared with control and mock-transfected cells. $(P<0.05$; Figure 10B $)$

\section{MiR-372 overexpression regulates MMP2, MMP9, PARP, and BAX mRNA or protein expression}

We performed qRT-PCR and Western blot to measured MMP2, MMP9, PARP, and Bax mRNA or protein expression levels after transfection with the miR-
372 mimics in EC cells. mRNA or protein expression of MMP2 and MMP9 were decreased but the expression of cleaved PARP and Bax were increased by miR-372 compared with the negative controls $(P<0.05$; Figure $11 \mathrm{~A} \& 11 \mathrm{~B})$. Western blot analysis demonstrated the same trend in the tumor tissues of the HSA-372 group of nude mice $(P<0.05$; Figure 11C).

\section{DISCUSSION}

We found that the mRNA levels of miR-372 in EC tissue were lower than in normal tissues and lower in lymph nodes with metastases than in lymph nodes without metastases. In addition, miR-372 expression was lower in ER negative and PR negative tissue than ER positive and PR positive tissue. Patients who are ER and PR negative have significantly poorer disease-free survival than those who are ER and PR positive [10], as do those with lymph node metastases. Therefore, miR-372 may be an antioncogene in EC. This led us to transfect miR-372 into EC cells to investigate the influence of miR-372 in EC cell tumorigenesis and tumor progression.

Our results demonstrated that miR-372 suppressed the proliferation, migration, and invasion of cells, increased the percentage of cells in G1 phase and promoted the apoptosis of endometrial carcinoma cells. Lastly, we performed nude mice xenograft assays, and the results showed that miR-372 suppressed tumorigenesis

A
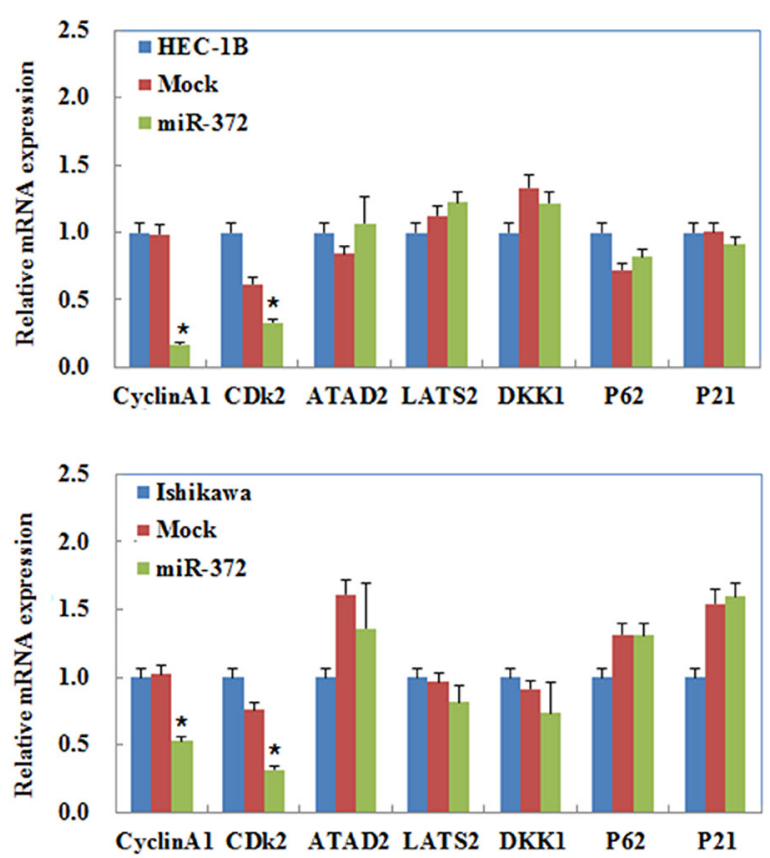

B

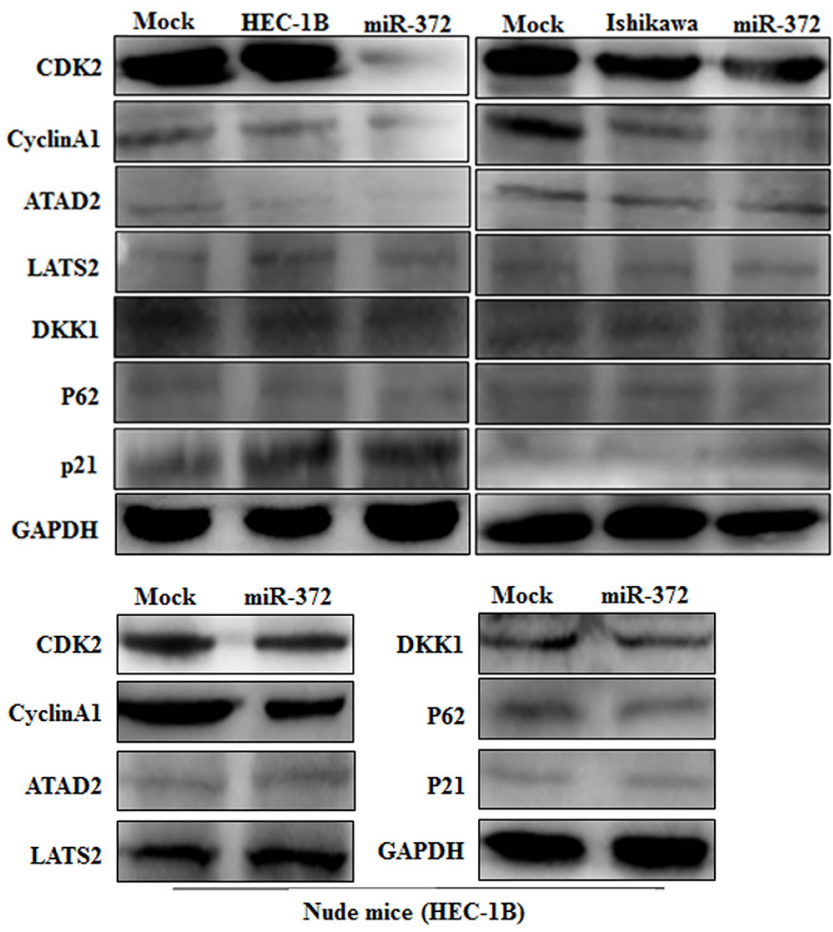

Figure 6: Effects of miR-372 transfection on endometrial adenocarcinoma cell genotype in vitro and in vivo. miR-372 overexpression reduced Cyclin A1, CDK2, however, no significant differences were found in ATAD2, Lats2, P21, P62, and DKK1 expression when compared with mock and control in vitro A \& B. and in vivo $\mathbf{C}$. $* P<0.05$. 
A

\section{C hsa-miR-372/RHOC Alignment}

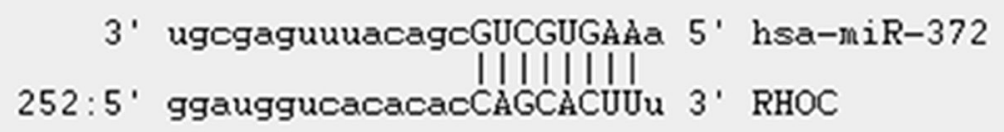

B

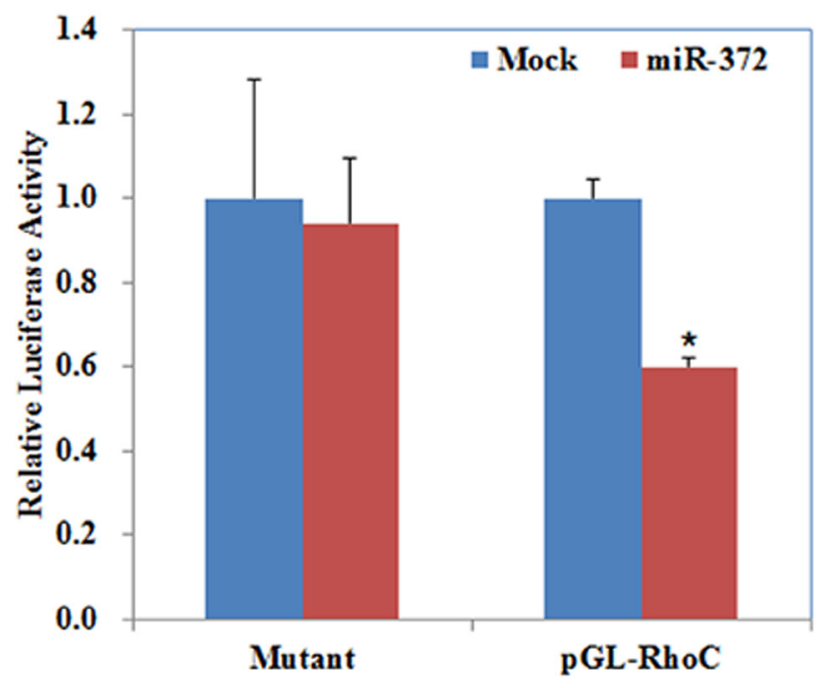

C

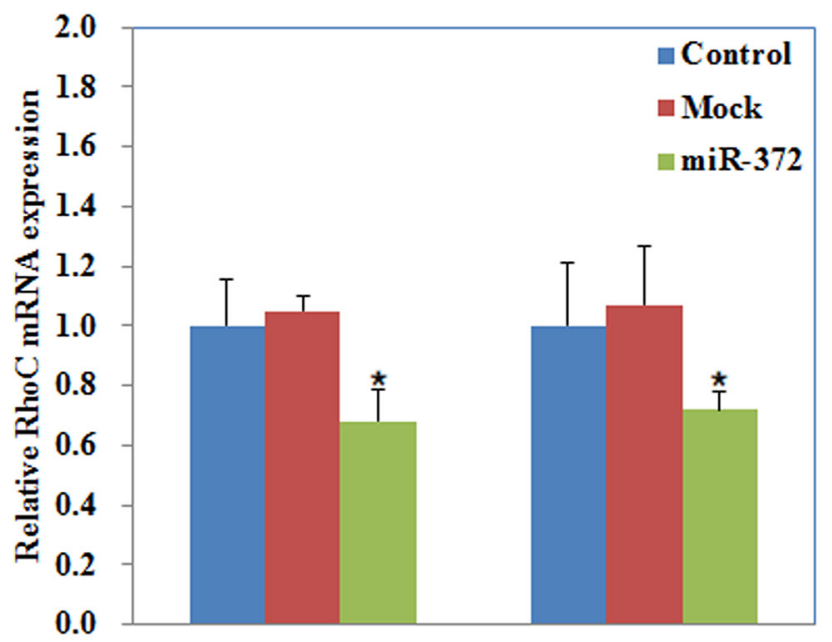

HEC-1B Ishikawa

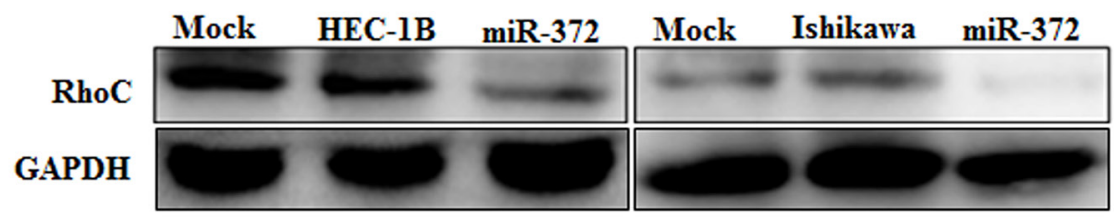

Figure 7: RhoC is a target of miR-372. The predicted seed region in the $3^{\prime}$ UTR of RhoC showed that RhoC was a direct target of miR-372 A. dual-luciferase reporter assay indicated that miR-372 directly targeted RhoC by binding its 3'UTR B. miR-372 transfection reduced the expression of RhoC at the mRNA and protein levels $\mathbf{C} . * P<0.05$. 
and tumor growth. These results all demonstrate an antioncogene role of miR-372 in endometrial carcinoma, which is consistent with the role of miR-372 in cervical carcinoma and hepatic carcinogenesis but is contrary to the role of miR-372 in testicular germ cell tumors, hESCs, HNSCC, and colorectal cancer.

MiR-372 suppresses the growth of cervical cancer cells by downregulating cyclin A1 and CDK2 [11]. MiR-372 plays an anti-oncogenetic role through the downregulation of ATAD2 expression in hepatic carcinogenesis [12]. MiR-372 can possibly directly inhibit the expression of the tumor-suppressor Lats2 to promote the development of human testicular germ cell tumors [13]. In a previous study, it was shown that miR-372 could target $\mathrm{p} 21$, a tumor suppressor gene, to influence the division of hESCs [14]. MiR-372 decreases p62, thus increasing the motility of HNSCC cells in vitro and in vivo [15]. A previous study has shown that miR-372 promotes tumor cell proliferation and invasion by modulating DKK1 levels in colorectal cancer [16]. Because microRNA plays a role in tumorigenesis by downregulating its target genes at the post-transcriptional level, we examined the expression levels of Cyclin A1/ CDK2, ATAD2, Lats2, P21, P62, and DKK1 in EC cells transfected with miR-372 by qRT-PCR and Western blot. Our results demonstrated that Cyclin A1 and CDK2 mRNA and protein levels decreased compared with the negative control; however, ATAD2, Lats2, P21, P62, and DKK1 showed no significant difference at the mRNA and protein level. Therefore, we determined the expression of them in the tumor tissue from the HSA-372 group of nude mice and found the results to be consistent. The cyclin A1-CDK2 complex is crucial for successful DNA replication and normal cell cycle progression [11]. CDK2 is thought to be essential in the mammalian cell cycle and functions by driving cells through $\mathrm{S}$ phase in conjunction with A-type cyclins [17]. CDK2 is expressed at a higher level at the invasive front of EC than it is more deeply within the tumor EC [18]. CDK2 overexpression may be involved in the development and/or progression of human EC [19]. CDK2 expression gradually increases from normal through hyperplasia to carcinoma, indicating its potential importance in both early and late carcinogenesis in EC [20]. Cyclins are regarded as the major regulators of the cell cycle [2122]. Cyclin A1 is an alternative that is present at very low levels in cells during G0 but it increases throughout the progression of the cell cycle and reaches its highest levels in the $\mathrm{S}$ and G2/M phases [23]. The expression of cyclin A1 was significantly high in EC than in normal tissues [24]. Therefore, the anti-oncogenic role of miR372 in endometrial carcinoma may be similar to its role in cervical carcinoma through the downregulation of Cyclin A1 and CDK2 expression.

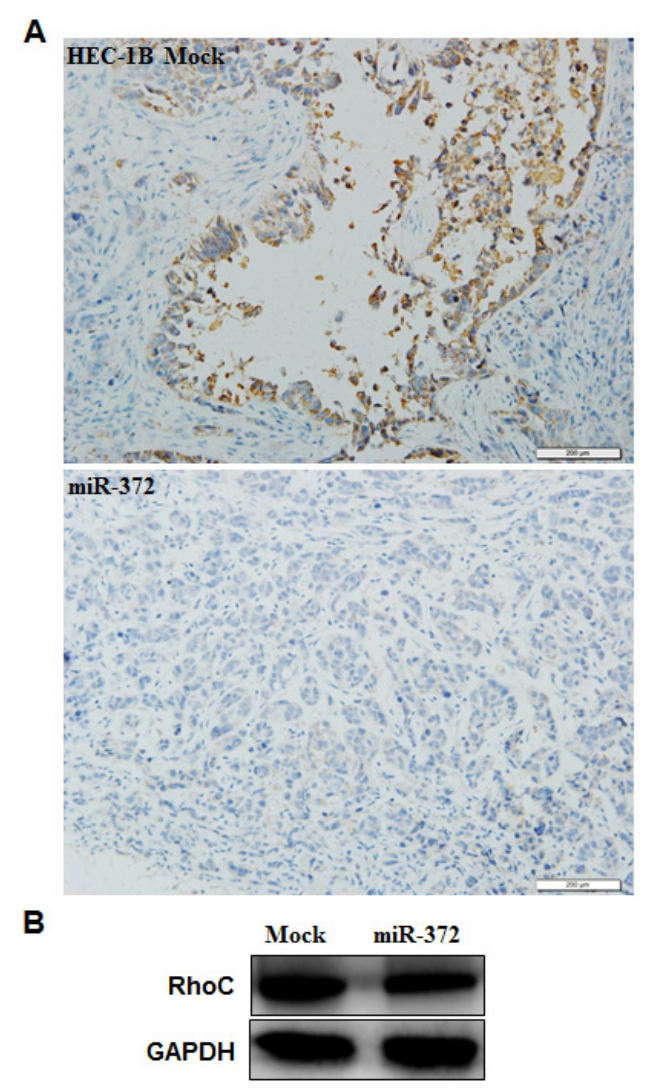

Figure 8: Effects of miR-372 transfection in vivo. Immunohistochemical and Western blot analysis demonstrated a significant reduction of RhoC expression in the HSA-372 group compared with the control group in nude mice tumor tissues $\mathbf{A} \& \mathbf{B}$. $* P<0.05$. 
Interestingly, we found another target of miR-372 in endometrial carcinoma, namely RhoC, which is involved in the tumorigenesis and development of many kinds of malignant tumors in humans. According to the 3'UTR of miR-372 and luciferase reporter assays, we found that
RhoC is a direct target of miR-372. We confirmed this observation by showing that the expression levels of RhoC in miR-372-transfected cells and in the tumor tissues of the HSA-372 group of nude mice were downregulated after transfection or injection, respectively.
A

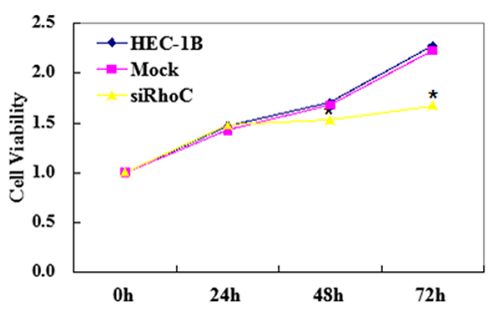

B
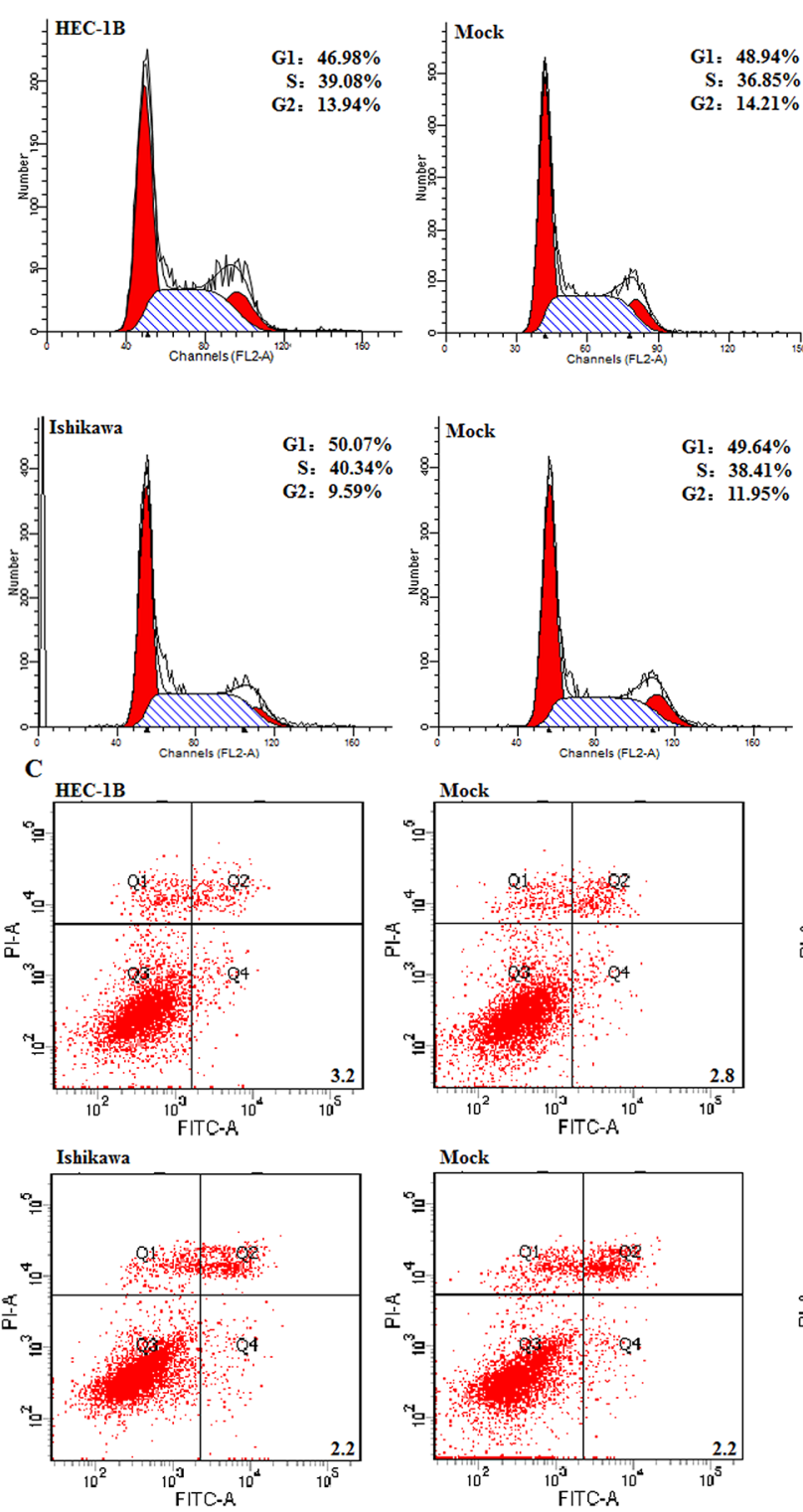
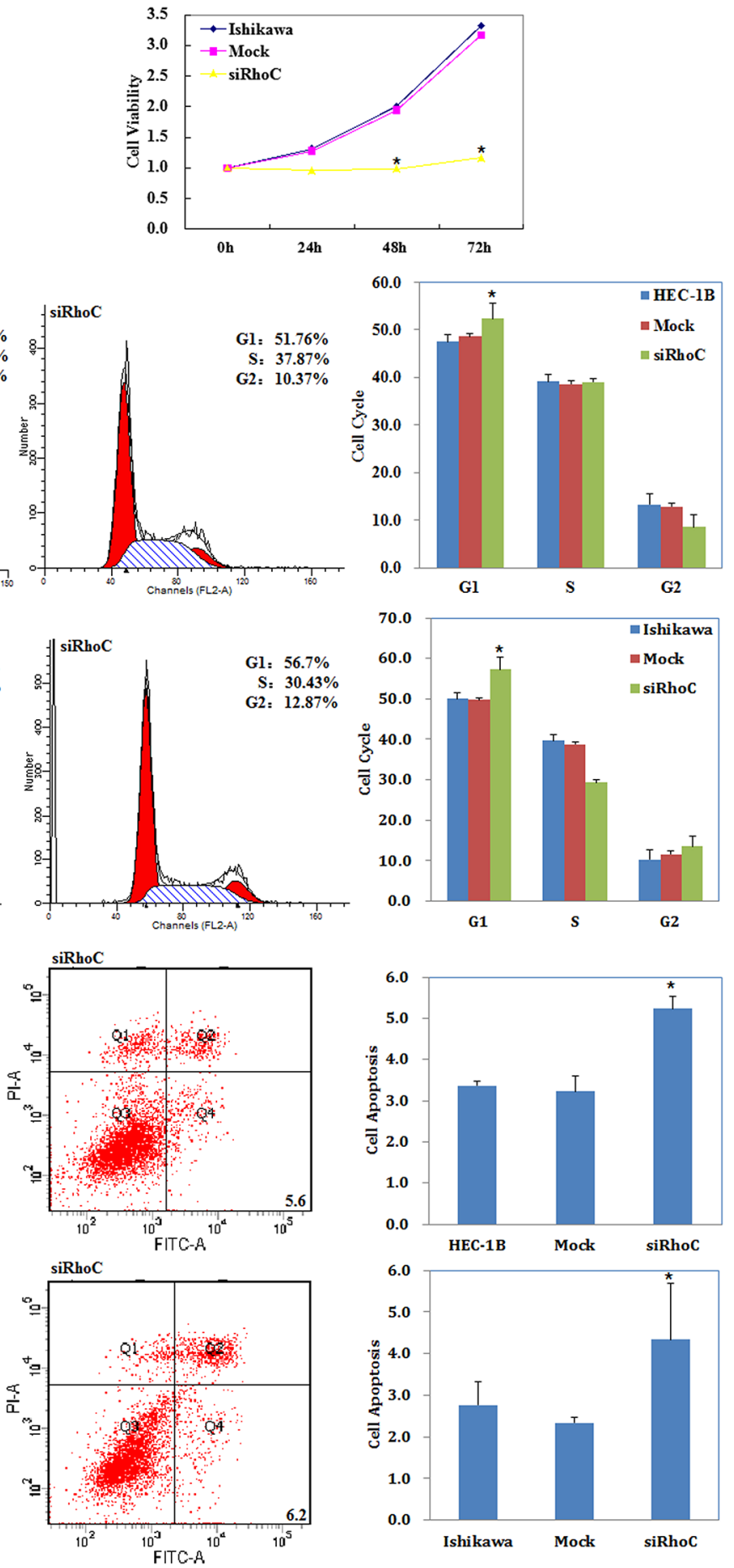

Figure 9: siRhoC suppresses endometrial carcinoma cell proliferation, induces G1 phase arrest and promotes apoptosis of endometrial carcinoma cells. Following siRhoC transfection, endometrial adenocarcinoma cell lines exhibited significantly slower growth A. G1 arrest B. and elevated apoptosis C. compared with the control and mock cells. Results are representative of three separate experiments; data are expressed as the mean \pm standard deviation, ${ }^{*} P<0.05$. 
RhoC belongs to the highly conserved Ras homologous subfamily, which plays an important role in tumor cell metastasis and invasion [25]. Upregulated expression of $\mathrm{RhoC}$ is related to the metastasis and invasiveness of many kinds of human malignant tumors, such as non-small cell lung carcinoma and hepatocellular carcinoma cells [26-37] and is correlated with a poorer prognosis in patients with pancreatic adenocarcinoma and ovarian carcinoma [38-41]. Furthermore, RhoC promotes the proliferation of gastric cancer cells [42]
A

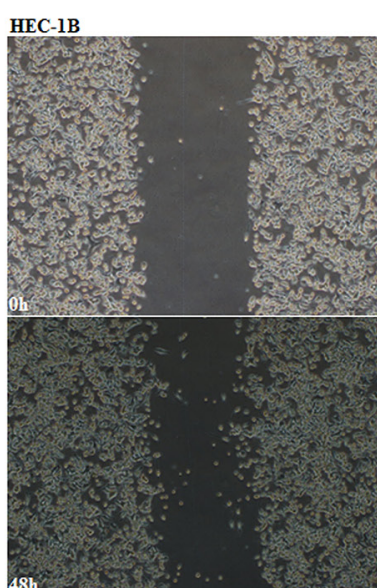

Ishikawa
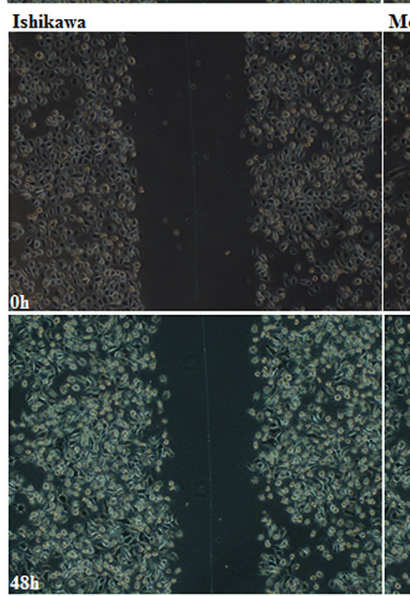

B

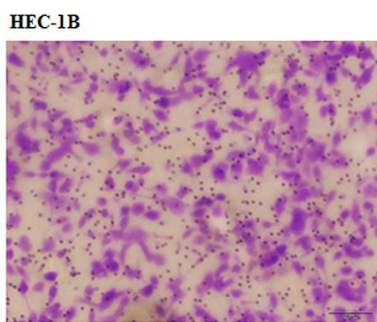

Ishikawa

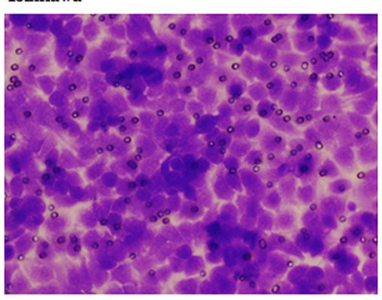

Mock

Mock

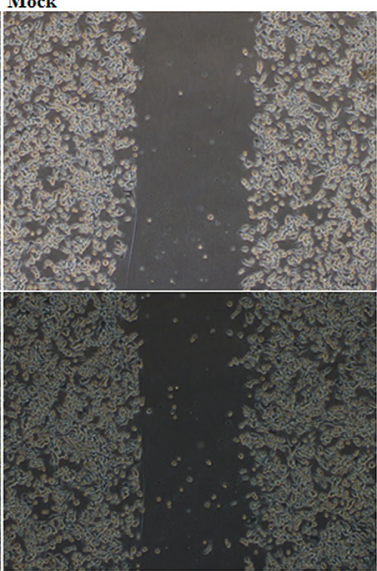

siRhoC

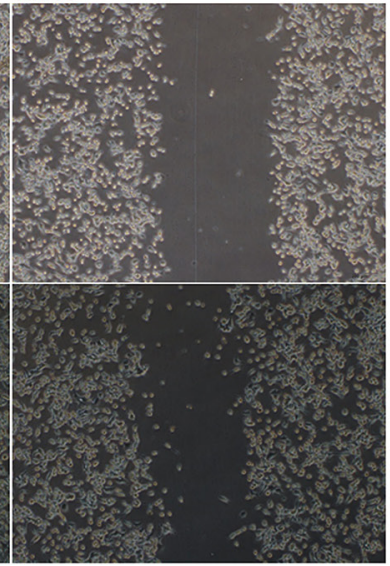

siRhoC

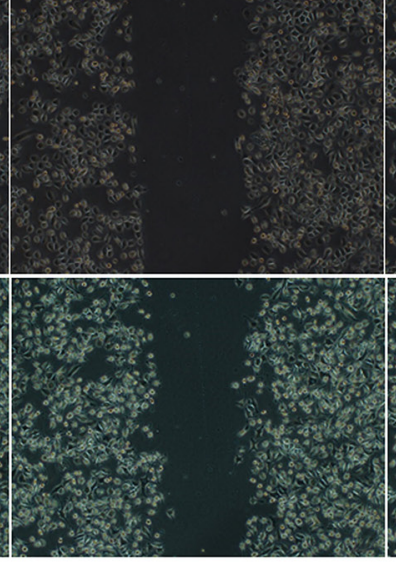

Mock

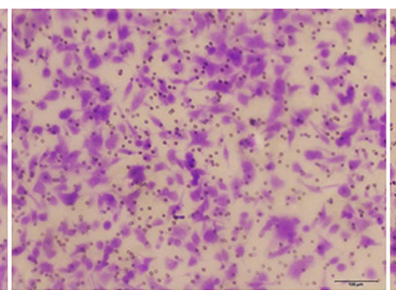

Mock
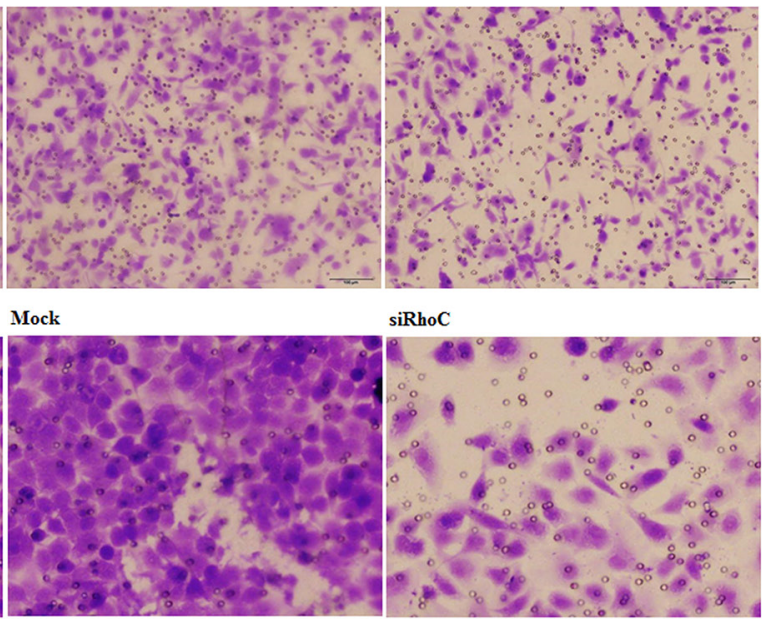

siRhoC

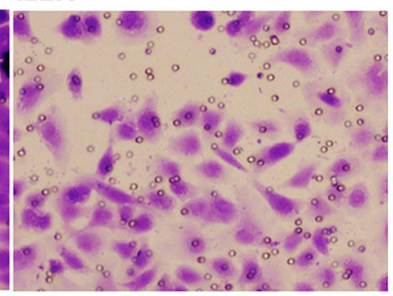

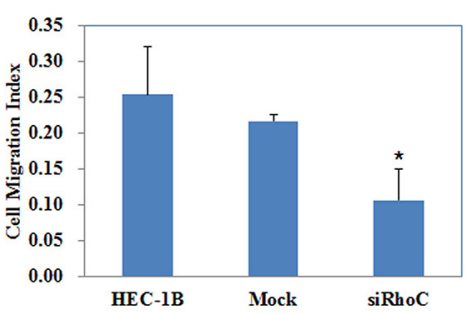
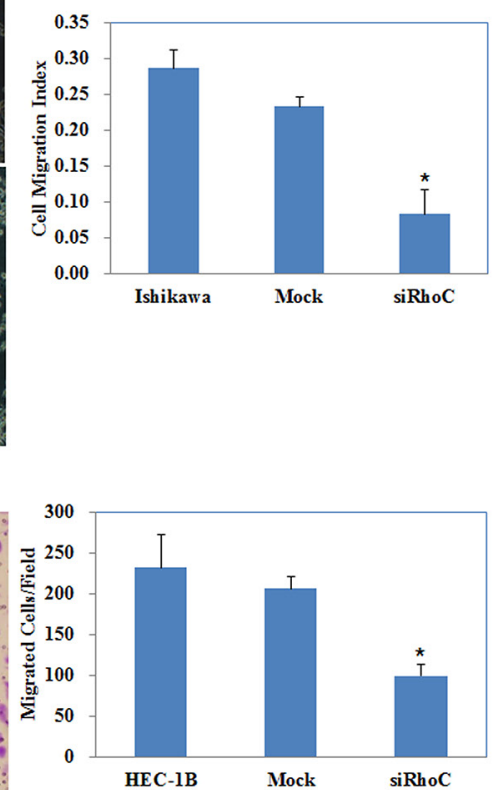

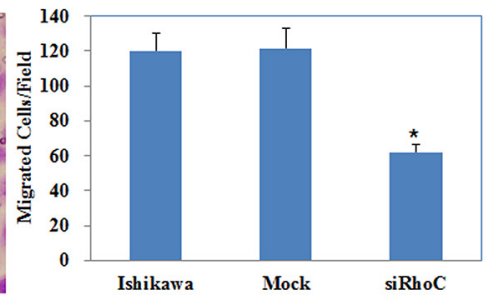

Figure 10: Effects of siRhoC transfection on invasive and metastatic ability of endometrial adenocarcinoma cell lines in vitro. siRhoC transfection exhibited lower migration in wound healing assays A. and slower invasion in transwell assays B. compared with the control and mock cells. Results are representative of three separate experiments; data are expressed as the mean \pm standard deviation, ${ }^{*} P<0.05$. 
and inflammatory breast cancer (IBC) [43] and regulates apoptosis of hepatocellular carcinoma cells [44]. Thus we knocked out RhoC by siRhoC transfection in EC cells and found that their proliferation, migration and invasion ability was suppressed, besides, RhoC downregulation caused G1 phase arrest and promoted cell apoptosis. Consequently, we suggest that the anti-oncogenetic effect of miR-372 in EC may be through targeting the downregulation of RhoC. This led us to determine the expression of relevant genes [45-51], which are involved in the promoting role of RhoC in malignant tumors after transfection with miR-372 in EC cells. We found that the expression levels of MMP2 and MMP9 were consistent with RhoC and contrary to miR372, but that cleaved PARP and BAX exhibited the opposite trend. Moreover, their expression in the tumor tissues of the HSA-372 group of nude mice showed the same trend. Taken together, these results demonstrate that miR-372 inhibits the tumorigenesis and development of endometrial cancer by targeting RhoC through the regulation of a series of relevant genes.

MicroRNA and their specific targets are dependent on the specific cellular environment [52]. Therefore, the miR372/RhoC pathway and the miR-372/Cyclin A1 and CDK2 pathway may collectively be involved in the anti-oncogenic properties of miR-372 in endometrial carcinoma. The present research is first to indicate the anti-oncogenetic role of miR-372 in endometrial carcinoma, and it may provide a new insight into the diagnosis and therapy of endometrial carcinoma.

\section{MATERIALS AND METHODS}

\section{Endometrial carcinoma specimens}

63 Endometrial adenocarcinomas (ECs) and 20 normal endometrial specimens were collected from patients who underwent surgical resection at the Department of Gynecology of the First Affiliated Hospital of China Medical University (Shenyang, Liaoning, China). Of the EC cases, 53 underwent lymph node dissection. The tumor specimens were independently confirmed by two pathologists. Samples were frozen immediately in liquid nitrogen and stored at $-80^{\circ} \mathrm{C}$ until use. None of the patients had preoperative chemotherapy or radiotherapy. Informed consent was obtained from all subjects, the study was approved by the China Medical University Ethics Committee, and all specimens were handled and made anonymous according to ethical and legal standards.
A
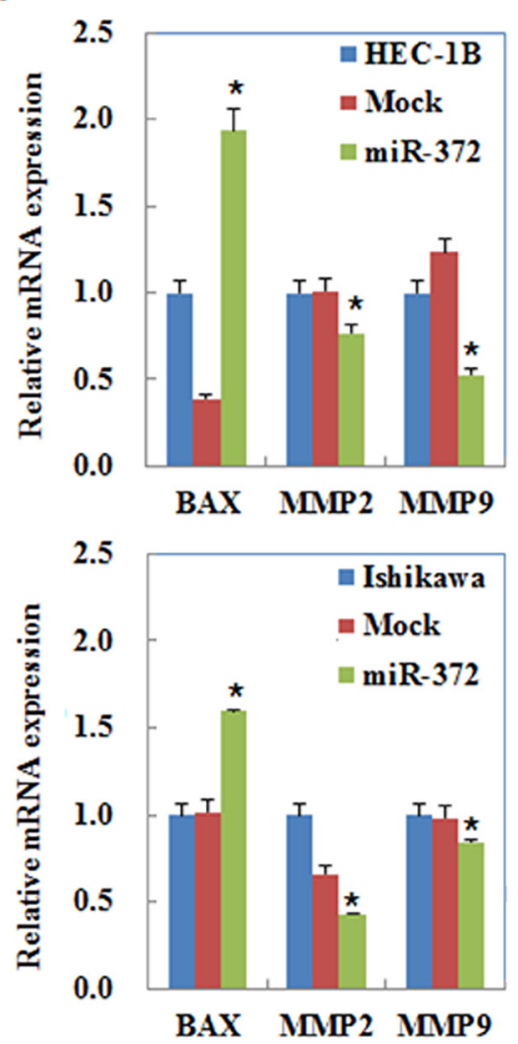

B

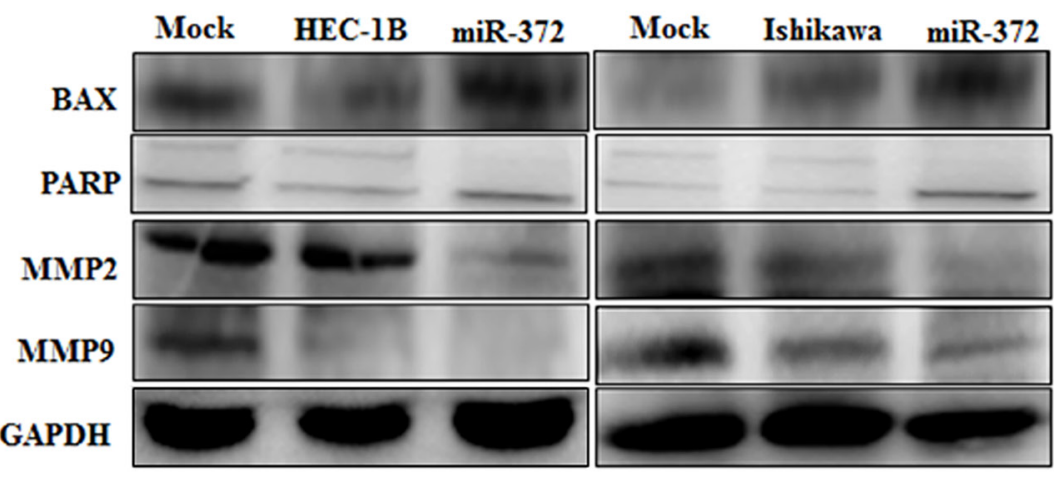

C

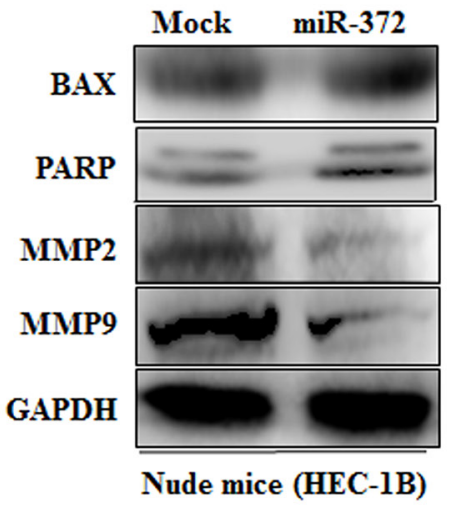

Figure 11: MiR-372 overexpression regulates MMP2, MMP9, PARP, and BAX mRNA or protein expression. QRT-PCR and Western blot results showed that mRNA or protein expression of MMP2 and MMP9 were decreased but the expression of cleaved PARP and Bax were increased by miR-372 compared with the negative controls A \& B. Western blot analysis demonstrated the same trend in the tumor tissues of the HSA-372 group of nude mice $\mathbf{C}$. 


\section{Cell culture and transfection}

The human endometrial carcinoma cell lines HEC-1B and Ishikawa were obtained from the Tumor Cell Bank of the Chinese Academy of Medical Science (Peking, China). The HEC-1B cells were cultured in Modified Eagle's Medium (DMEM; HyClone, Logan, UT, USA) and Ishikawa cells were cultured in RPMI 1640 (HyClone, Logan, UT, USA) supplemented with penicillin/streptomycin $(100 \mathrm{U} / \mathrm{ml})$ with $10 \%$ fetal bovine serum (FBS) under conditions of $5 \% \mathrm{CO}_{2}$ at $37^{\circ} \mathrm{C}$. All transfections were carried out using Lipofectamine 2000 according to the manufacturer's instructions. The concentration of miR-372 (Biomics Biotech, Jiangsu, China) was $50 \mathrm{nM}$. The sequence of miR-372 mimic was 5'-AAAGUGCUGCGACAUUUGAGC GUGCUCAAAUGUCGCAGCACUUUUU- $3^{\prime}$. The target sequences of RhoC siRNA were 5'-GUGCCUUUGG CUACCUUGAdTdT-3' (sense) and 5'-UCAAGGUA GCCA AAGGCACdTdT-3' (anti-sense).

\section{MTT assay}

The cells were seeded in 96-well plates at a density of 3,000 cells/well for different periods. At a given time point $(0 \mathrm{~h}, 24 \mathrm{~h}, 48 \mathrm{~h}$, and $72 \mathrm{~h})$ after transient transfection, the cells were incubated with $20 \mu \mathrm{l}$ of $5 \mathrm{mg} / \mathrm{ml}$ MTT (Solarbio, Beijing, China) at $37^{\circ} \mathrm{C}$ for another $4 \mathrm{~h}$. Then the medium was removed, and the precipitated formazan was dissolved in $150 \mu \mathrm{l}$ of DMSO. After shaking for 10 min, the absorbance at $490 \mathrm{~nm}$ was detected using a microplate spectrophotometer (Bio-Tek Instruments, Winooski, VT).

\section{Cell cycle analysis}

The cells were trypsinized, collected, washed, and fixed in $70 \%$ ice-cold ethanol for at least $12 \mathrm{~h}$, and then were washed again and resuspended in buffer solution $(400 \mu \mathrm{l})$ with RNaseA $(0.125 \mathrm{mg})$ at $37^{\circ} \mathrm{C}$ for $30 \mathrm{~min}$. The cells were stained with propidium iodide $(100 \mu \mathrm{l})(\mathrm{PI}$; Key Gen, Nanjing, China) and incubated at $4^{\circ} \mathrm{C}$ in the dark for $30 \mathrm{~min}$. The cell cycle profiles were determined by flow cytometer.

\section{Apoptosis assay}

Briefly, cells were harvested at $2000 \mathrm{r} / \mathrm{min}$ for 5 min and washed twice with cold PBS. Then cells were resuspended in $200 \mu \mathrm{L}$ binding buffer and $5 \mu \mathrm{L}$ annexin V-FITC at $1 \times 10^{6}$ cells $/ \mathrm{mL}$ and incubated for $15 \mathrm{~min}$ at room temperature in the dark. A total of $300 \mu \mathrm{L}$ binding buffer and $5 \mu \mathrm{L}$ PI were added to each tube, and the cell apoptosis rate was determined by flow cytometer within $1 \mathrm{~h}$.

\section{Wound-healing assay}

Cells were cultured to $80 \%$ confluence in 6-well culture plates before scratched with a $200 \mu \mathrm{l}$ pipette tip. After scratching, cells were washed with PBS and cultured in FBS-free medium. Wounds were observed by microscope and photographed at $0 / 24 / 48 \mathrm{~h}$. The nude areas were measured using Image $\mathbf{J}$ software (National Institutes of Health, Bethesda, MD, USA). The wound healing rate $=($ Area of original wound - Area of actual wound at different times)/Area of original wound $\times 100 \%$.

\section{Invasion assay}

Matrigel coated transwell cell culture chambers (BD Bioscience, San Jose, CA, USA) were used for the invasion assay. Filters were coated with $30 \mu \mathrm{l}$ of basement membrane Matrigel at a dilution of $1: 10$. Cells $\left(5^{*} 10^{4} / \mathrm{L}\right)$ resuspended in $200 \mu \mathrm{l}$ serum-free medium were layered in the upper compartment of transwell inserts. The bottom chambers contained $600 \mu \mathrm{l}$ complete medium serving as the chemoattractants. After incubation for $48 \mathrm{~h}$ at $37^{\circ} \mathrm{C}$, cells on the upper surface of the filter were removed using a cotton swab and invaded cells at the bottom of the upper chamber were fixed with formaldehyde, stained with crystal violet, and counted under an Olympus fluorescence microscope (Tokyo, Japan).

\section{Real-time RT-PCR}

Total RNA was isolated from endometrial carcinoma cell lines and tissues with TRIzol reagent (Takara, Shiga, Japan) and was reverse transcribed to cDNA using an avian myeloblastosis virus transcriptase and random primers (Takara, Shiga, Japan) according to the manufacturer's protocol. Then the cDNA was amplified by real-time quantitative PCR with SYBR Premix Ex Taq тм II kit (Takara, Shiga, Japan). The expression level of each target gene was normalized to $18 \mathrm{~s}$ mRNA. The data analysis was calculated according to the sample threshold cycle $(\mathrm{Ct})$ value from three independent experiments. Hairpin-it ${ }^{\mathrm{TM}}$ microRNA and U6 snRNA Normalization RT-PCR Quantitation (GenePharma) were used to check mature miR-372.

\section{Western blotting}

The total cell proteins were harvested and lysed in RIPA buffer containing protease inhibitors. $40 \mu \mathrm{g}$ protein lysates were separated on $10 \%$ SDS-polyacrylamide gel and electrotransferred to Hybond membranes (Amersham, Munich, Germany). Fat-free milk (5\%) was used to block membranes for $2 \mathrm{~h}$ at room temperature. After blocking, primary antibodies, including RhoC (1:500, Santa Cruz Biotechnology, Santa Cruz, CA, USA), 
MMP2, MMP9, PARP, Bax, CyclinA1, CDK2, ATPase family AAA domain-containing protein2 (ATAD2), large tumor suppressor 2 (Lats2), Cyclin-dependent kinase inhibitor 1A (P21), sequestosome1 (P62), and Dickkopf-1 (DKK1) (1:500, Proteintech, Proteintech Group, USA) were incubated with the blot overnight at $4^{\circ} \mathrm{C}$. The next day, the secondary antibody (1:5000) was added for 2 $\mathrm{h}$ at room temperature after the membrane was washed three times with TBST. Protein was visualized using an enhanced chemiluminescence (ECL) system according to the manufacturer's protocol (Santa Cruz Biotechnology, Santa Cruz, CA, USA). Anti-GAPDH (1:2000, Proteintech Group, USA) was used as the inner control.

\section{Immunohistochemistry}

Paraffin-embedded tissue sections were deparaffinized in xylene and rehydrated in a graded series of ethanol solutions and then incubated for $20 \mathrm{~min}$ in $3 \% \mathrm{H}_{2} \mathrm{O}_{2}$ to quench the endogenous peroxidase activity. Next, the sections were heated in target retrieval solution (Dako) for $15 \mathrm{~min}$ in a microwave oven (Oriental Rotor) to retrieve the antigen. Non-specific binding was blocked by incubating with $10 \%$ goat serum for $2 \mathrm{~h}$ at room temperature. The slides were then incubated over night at $4^{\circ} \mathrm{C}$ with anti-RhoC primary antibodies. Subsequently, an appropriate secondary antibody was added and incubated for $1 \mathrm{~h}$ at $37^{\circ} \mathrm{C}$, and the binding was visualized with 3 , 39-diaminobenzidine tetrahydrochloride (DAB). After each treatment, the slides were washed three times with TBST for $5 \mathrm{~min}$.

\section{In vivo nude mouse xenograft assay}

All animal experiments were undertaken in accordance with the National Institutes of Health Guide for the Care and Use of Laboratory Animals with the approval of China Medical University Animal Care and Use Committee. Female BALB/c nude mice, 4-6-weeksold were obtained from Vital River Laboratories (VRL; Beijing, China) and were routinely housed in light (12 h dark/12 h light) and temperature-controlled rooms. Animals had free access to food and water. HEC-1B [53] cells $(1 \times$ $10^{7}$ ) were transfected with mutant or wild HSA-372 were resuspended in $200 \mu \mathrm{L}$ FBS-free culture medium, and injected subcutaneously into the right flanks of mice. The tumor volume and tumor weight was measured routinely following inoculation using direct measurement and calculated using the formula (length $\times$ width $\left.^{2}\right) / 2$.

\section{Dual-luciferase reporter assay}

HEK293T cells were co-transfected with either RhoC 3'UTR clone or negative control clone and miR372 or scramble control using Lipofectamine 2000 reagent $24 \mathrm{~h}$ after plating in 24-well plates. PRL-TK vector expressing renilla luciferase was used as the transfection control. Cell extracts were prepared $48 \mathrm{~h}$ after transfection, and luciferase activity was measured using the DualLuciferase Reporter Assay System (Promega, USA) according to the manufacturer's protocol. The ratio of firefly to renilla luciferase signal was used to normalize firefly activity for intra-experimental transfection efficiency. The wild sequence for RhoC (NM_001042679) 3' UTR: AGCCACGCCTATGCCCTGCCCTTCCTCAGGGCCCCT GGGGATCTTGCCCCCTTTGACCTTCCCCAAAGGAT GGTCACACACCAGCACUUTTACACTTCTGGCTCAC AGGAAAGTGTCTGCAGTAGGG; while mutant was AGCCACGCCTATGCCCTGCCCTTCCTCAGGGCCCCT GGGGATCTTGCCCCCTTTGACCTTCCCCAAAG GAT GGTCACACACCUAUACGCTTACACTTC TGGCTCA CAGGAAAGTGTCTGCAGTAGGG (Shanghai Genechem Co.,Ltd, Shanghai, China).

\section{Statistical analyses}

Statistical analyses were performed using SPSS 17.0 (SPSS, Chicago, IL, USA). The differences among groups, in at least three separate experiments, were analyzed using a double-sided Student's $t$-test. $P<0.05$ was considered to indicate a statistically significant difference.

\section{ACKNOWLEDGMENTS}

This work was supported by Natural Scientific Foundation of China (Nos. 81202049; 81472440; 81472502) and Liaoning Science and Technology Grant (L2013021077).

\section{CONFLICTS OF INTEREST}

None.

\section{REFERENCES}

1. Jamison PM, Noone AM, Ries LA. Trends in endometrial cancer incidence by race and histology with a correction for the prevalence of hysterectomy, SEER 1992 to 2008. Cancer Epidemiol Biomarkers Prev. 2013; 22:233-41.

2. American Cancer Society. American Cancer Society Facts \& Figures 2015. Atlanta, GA: American Cancer Society; 2015.

3. Ambros V. The functions of animal microRNAs. Nature. 2004; 431:350-355.

4. Bartel DP. MicroRNAs: genomics, biogenesis, mechanism, and function. Cell. 2004; 116:281-97.

5. Garzon R, Calin GA, Croce CM. MicroRNAs in Cancer. Annu Rev Med. 2009; 60:167-79.

6. Carleton M, Cleary MA, Linsley PS. MicroRNAs and cell cycle regulation. Cell Cycle. 2007; 6:2127-32. 
7. Harfe BD. MicroRNAs in vertebrate development. Curr. Opin. Genet. Dev. 2005; 15:410-15.

8. Lau NC, Lim LP, Weinstein EG. An abundant class of tiny RNAs with probable regulatory roles inCaenorhabditis elegans. Science. 2001; 294:858-62.

9. Boehm M, Slack FJ. MicroRNA control of lifespan and metabolism. Cell Cycle. 2005; 5:837-40.

10. CreasmanWT. Prognostic significance of hormone receptors in endometrial cancer. Cancer. 1993; 71:1467-70.

11. Tian RQ, Wang XH, Hou LJ, Jia WH, Yang Q, Li YX, Liu M, Li X, Tang H. MicroRNA-372 is down-regulated and targets cyclin-dependent kinase 2 (CDK2) and cyclin A1 in human cervical cancer, which may contribute to tumorigenesis. J Biol Chem. 2011; 286: 25556-25563.

12. Wu G, Liu HY, He H, Wang YW, Lu XJ, Yu YQ, Xia SG, Meng XY and Liu YF. miR-372 down-regulates the oncogene ATAD2 to influence hepatocellular carcinoma proliferation and metastasis. BMC Cancer. 2014; 14:107-117.

13. Voorhoeve PM, le Sage C, Schrier M, Gillis AJ, Stoop H, Nagel R, Liu YP, van Duijse J, Drost J, Griekspoor A, Zlotorynski E, Yabuta N, De Vita G, et al. A Genetic Screen Implicates miRNA-372 and miRNA-373 As Oncogenes inTesticular Germ Cell Tumors. Cell 2006; 124:1169-1181.

14. Qi J, Yu JY, Shcherbata HR, Mathieu J, Wang AJ, Seal S, Zhou W, Stadler BM, Bourgin D, Wang L, Nelson A, Ware $\mathrm{C}$, Raymond C, et al. microRNAs regulate human embryonic stem cell division. Cell Cycle. 2009; 8: 3729-3741.

15. Yeh LY, Liu CJ, Wong YK, Chang C, Lin SC, Chang KW. miR-372 inhibits p62 in head and neck squamous cell carcinoma in vitro and in vivo. Oncotarget. 2015; 6:6062-75 doi: 10.18632/oncotarget.3340.

16. Zhou AD, Diao LT, Xu H, Xiao ZD, Li JH, Zhou H, Qu LH. $\beta$-Catenin/LEF1 transactivates the microRNA-371-373 cluster that modulates the $\mathrm{Wnt} / \mathrm{b}$-catenin-signaling pathway. Oncogene. 2012; 31:2968-2978.

17. Ortega S, Prieto I, Odajima J, Martín A, Dubus P, Sotillo R, Barbero JL, Malumbres M, Barbacid M. Cyclin-dependent kinase 2 is essential for meiosis but not for mitotic cell division in mice. Nat Genet. 2003; 35:25-31.

18. Horrée N, van Diest PJ, Sie-Go DM, Heintz AP. The invasive front in endometrial carcinoma: higher proliferation and associated derailment of cell cycle regulators. Hum Pathol. 2007; 38:1232-8.

19. Ito K, Sasano H, Yoshida $\mathrm{Y}$, Sato S, Yajima A. Immunohistochemical study of cyclins $\mathrm{D}$ and $\mathrm{E}$ and cyclin dependent kinase (cdk) 2 and 4 in human endometrial carcinoma. Anticancer Research. 1998; 18:1661-1664.

20. Horrée N, van Diest PJ, van der Groep P, Sie-Go DM, Heintz AP. Progressive derailment of cell cycle regulators in endometrial carcinogenesis. J Clin Pathol. 2008; 61:36-42.

21. Obaya AJ, Sedivy JM. Regulation of cyclin-Cdk activity in mammalian cells. Cell Mol Life Sci. 2002; 59:126-42.
22. Murray AW, Solomon MJ, Kirschner MW. The role of cyclin synthesis and degradation in the control of maturation promoting factor activity. Nature. 1989; 339:280-6.

23. Yang R, Müller C, Huynh V, Fung YK, Yee AS, Koeffler HP. Functions of cyclin A1 in the cell cycle and its interactions with transcription factor E2F-1 and the Rb family of proteins. Mol. Cell. Biol. 1999; 19:2400-7.

24. Müller-Tidow C, Diederichs S, Schrader MG, Vogt U, Miller K, Berdel WE, Serve H. Cyclin A1 is highly expressed in aggressive testicular germ cell tumors. Cancer Lett. 2003; 190:89-95.

25. Clark EA, Golub TR, Lander ES, Hynes RO. Genomic analysis of metastasis reveals an essential role for RhoC. Nature. 2000; 406:532-5.

26. Liu N, Zhang G, Bi F, Pan Y, Xue Y, Shi Y, Yao L, Zhao L, Zheng Y, Fan D. RhoC is essential for the metastasis of gastric cancer. J Mol Med (Berl). 2007; 85:1149-56.

27. Shikada Y, Yoshino I, Okamoto T, Fukuyama S, Kameyama T, Maehara Y. Higher expression of RhoC is related to invasiveness in non-small cell lung carcinoma. Clin Cancer Res. 2003; 9:5282-6.

28. van Golen KL, Wu ZF, Qiao XT, Bao LW, Merajver SD. RhoC GTPase, a novel transforming oncogene for human mammary epithelial cells that partially recapitulates the inflammatory breast cancer phenotype. Cancer Res. 2000; 60:5832-8.

29. Kleer CG, van Golen KL, Zhang Y, Wu ZF, Rubin MA, Merajver SD. Characterization of RhoC expression in benign and malignant breast disease: a potential new marker for small breast carcinomas with metastatic ability. Am J Pathol. 2002; 160:579-84.

30. Kondo T, Sentani K, Oue N, Yoshida K, Nakayama H, Yasui W. Expression of RhoC is associated with metastasis of gastric carcinomas. Pathobiology. 2004; 71:19-25.

31. Wang W, Wu F, Fang F, Tao Y, Yang L. Inhibition of invasion and metastasis of hepatocellular carcinoma cells via targeting RhoC in vitro and in vivo. Clin Cancer Res. 2008; 14:6804-12.

32. Hakem A, Sanchez-Sweatman O, You-Ten A, Duncan G, Wakeham A, Khokha R, Mak TW. RhoC is dispensable for embryogenesis and tumor initiation but essential for metastasis. Genes Dev. 2005; 19:1974-9.

33. Yao H, Dashner EJ, van Golen CM, van Golen KL. RhoC GTPase is required for PC-3 prostate cancer cell invasion but not motility. Oncogene. 2006; 25:2285-96.

34. Sequeira L, Dubyk CW, Riesenberger TA, Cooper CR, van Golen KL. Rho GTPases in PC-3 prostate cancer cell morphology, invasion and tumor cell diapedesis. Clin Exp Metastasis. 2008; 25:569-79.

35. Faried A, Faried LS, Kimura H, Nakajima M, Sohda M, Miyazaki T, Kato H, Usman N, Kuwano H. RhoA and RhoC proteins promote both cell proliferation and cell invasion of human oesophageal squamous cell carcinoma cell lines in vitro and in vivo. Eur J Cancer. 2006; 42:1455-65. 
36. Kleer CG, Teknos TN, Islam M, Marcus B, Lee JS, Pan Q, Merajver SD. RhoC GTPase expression as a potential marker of lymph node metastasis in squamous cell carcinomas of the head and neck. Clin Cancer Res. 2006; 12:4485-90.

37. Islam M, Lin G, Brenner JC, Pan Q, Merajver SD, Hou Y, Kumar P, Teknos TN. RhoC expression and head and neck cancer metastasis. Mol Cancer Res. 2009; 7:1771-80.

38. Suwa H, Ohshio G, Imamura $T$, Watanabe G, Arii $\mathrm{S}$, Imamura $\mathrm{M}$, Narumiya $\mathrm{S}$, Hiai $\mathrm{H}$, Fukumoto $\mathrm{M}$. Overexpression of the RhoC gene correlates with progression of ductal adenocarcinoma of the pancreas. Br J Cancer. 1998; 77:147-52.

39. Horiuchi A, Imai T, Wang C, Ohira S, Feng Y, Nikaido T, Konishi I. Up-regulation of small GTPases, RhoA and $\mathrm{RhoC}$, is associated with tumor progression in ovarian carcinoma. Lab Invest. 2003; 83:861-70.

40. Kamai T, Tsujii T, Arai K, Takagi K, Asami H, Ito Y, Oshima H. Significant association of Rho/ROCK pathway with invasion and metastasis of bladder cancer. Clin Cancer Res. 2003; 9:2632-41.

41. Wang W, Yang LY, Huang GW, Lu WQ, Yang ZL, Yang JQ, Liu HL. Genomic analysis reveals RhoC as a potential marker in hepatocellular carcinoma with poor prognosis. $\mathrm{Br}$ J Cancer. 2004; 90:2349-55.

42. $\mathrm{Wu} \mathrm{Y}$, Tao $\mathrm{Y}, \mathrm{Chen} \mathrm{Y}, \mathrm{Xu} \mathrm{W}$. RhoC regulates the proliferation of gastric cancer cells through interaction with IQGAP1. PLoS One. 2012; 7:e48917.

43. Wu M, Wu ZF, Kumar-Sinha C, Chinnaiyan A, Merajver $\mathrm{SD}$. RhoC induces differential expression of genes involved in invasion and metastasis in MCF10A breast cells. Breast Cancer Res Treat. 2004; 84:3-12.

44. Xie S, Zhu M, Lv G, Zhang Q, Wang G. The role of RhoC in the proliferation and apoptosis of hepatocellular carcinoma cells. Med Oncol. 2012; 29:1802-9.
45. Xie SL, Zhu MG, Lv GY, Geng YJ, Chen GF, Ma J, Wang GG. Overexpression of Ras Homologous C (RhoC) Induces Malignant Transformation of Hepatocytes In Vitro and in Nude Mouse Xenografts. PLOS ONE. 2013; 8:e54493.

46. Chen X, Chen S, Xiu YL, Sun KX, Zong ZH, Zhao Y. RhoC is a major target of microRNA-93-5P in epithelial ovarian carcinoma tumorigenesis and progression. MolCancer. 2015; 14:31.

47. Wang Q, Tang H, Yin S, Dong C. Downregulation of microRNA-138 enhances the proliferation, migration and invasion of cholangiocarcinoma cells through the upregulation of RhoC/p-ERK/MMP-2/MMP-9. Oncol Rep. 2013; 29:2046-52.

48. Zhao Y, Zheng HC, Chen S, Gou WF, Xiao LJ, Niu ZF. The role of RhoC in ovarian epithelial carcinoma: a marker for carcinogenesis, progression, prognosis, and target therapy. Gynecol Oncol. 2013; 130:570-8.

49. Ikoma T, Takahashi T, Nagano S, Li YM, Ohno Y, Ando K, Fujiwara T, Fujiwara H, Kosai K. A definitive role of RhoC in metastasis of orthotopic lung cancer in mice. Clin Cancer Res. 2004; 10:1192-200.

50. Zhao Y, Zong ZH, Xu HM. RhoC expression level is correlated with the clinicopathological characteristics of ovarian cancer and the expression levels of ROCK-I, VEGF, and MMP9. Gynecol Oncol. 2010; 116:563-71.

51. Chen S, Chen X, Xiu YL, Sun KX, Zhao Y. Inhibition of Ovarian Epithelial Carcinoma Tumorigenesis and Progression by microRNA $106 \mathrm{~b}$ Mediated through the RhoC Pathway. PLOS ONE.2015; 10:e125714.

52. Meltzer PS. Cancer genomics: Small RNAs with big impacts. Nature. 2005; 435:745-746.

53. Xiao Y, Teng Y, Zhang R, Luo L. Antitumor effect of the selective COX-2 inhibitor celecoxib on endometrial adenocarcinoma in vitro and in vivo. Oncol Lett. 2012 Dec; 4:1219-1224. 